\title{
Thirty-day incidence of stroke after transfemoral transcatheter aortic valve implantation: meta-analysis and mixt-treatment comparison of self-expandable versus balloon-expandable valve prostheses
}

\author{
Philipp C. Seppelt ${ }^{1,2} \mathbb{D} \cdot$ Silvia Mas-Peiro ${ }^{1,2} \cdot$ Roberta De Rosa $^{1} \cdot$ Zisis Dimitriasis $^{1,2} \cdot$ Andreas M. Zeiher $^{1,2}$. \\ Mariuca Vasa-Nicotera ${ }^{1,2}$
}

Received: 10 August 2020 / Accepted: 28 October 2020 / Published online: 29 November 2020

(c) The Author(s) 2020

\begin{abstract}
Aims Stroke is a major complication after transcatheter aortic valve implantation (TAVI). Although multifactorial, it remains unknown whether the valve deployment system itself has an impact on the incidence of early stroke. We performed a metaand network analysis to investigate the 30-day stroke incidence of self-expandable (SEV) and balloon-expandable (BEV) valves after transfemoral TAVI.

Methods and results Overall, 2723 articles were searched directly comparing the performance of SEV and BEV after transfemoral TAVI, from which 9 were included (3086 patients). Random effects models were used for meta- and network meta-analysis based on a frequentist framework. Thirty-day incidence of stroke was $1.8 \%$ in SEV and 3.1\% in BEV (risk ratio of $0.62,95 \%$ confidence interval $(\mathrm{CI}) 0.49-0.80, p=0.004)$. Treatment ranking based on network analysis (P-score) revealed CoreValve with the best performance for 30-day stroke incidence (75.2\%), whereas SAPIEN had the worst (19.0\%). However, network analysis showed no inferiority of SAPIEN compared with CoreValve (odds ratio 2.24, 95\% CI 0.70-7.2). Conclusion Our analysis indicates higher 30-day stroke incidence after transfemoral TAVI with BEV compared to SEV. We could not find evidence for superiority of a specific valve system. More randomized controlled trials with head-to-head comparison of SEV and BEV are needed to address this open question.
\end{abstract}

Philipp C. Seppelt

Philipp.Seppelt@kgu.de

1 Division of Cardiology, Department of Medicine III,

University Hospital, Goethe University Frankfurt,

Frankfurt am Main, Germany

2 DZHK partner site Rhine-Main, German Centre for Cardiovascular Research, Berlin, Germany 


\section{Graphic abstract}

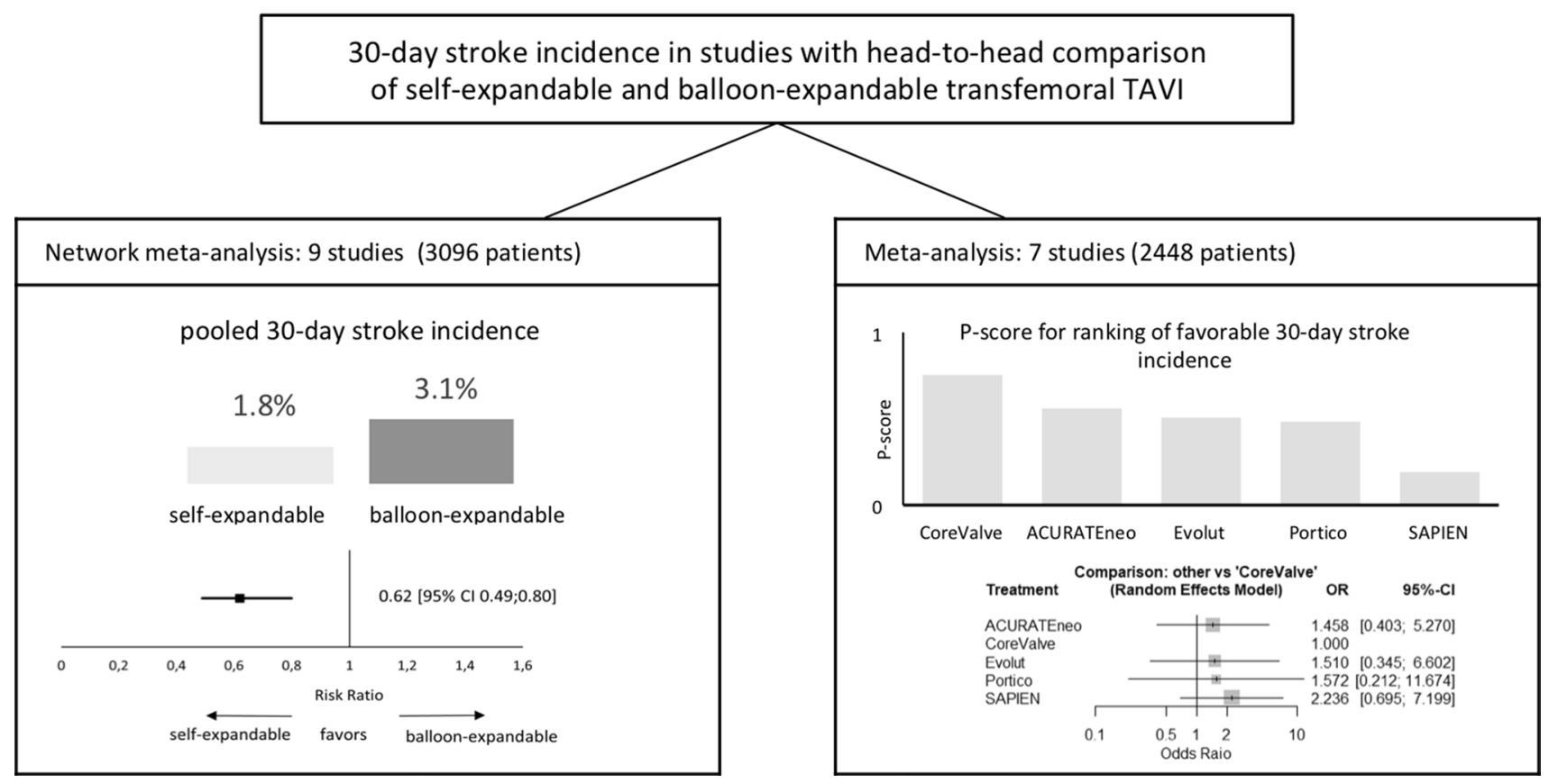

Keywords Aortic stenosis $\cdot$ Stroke $\cdot$ Balloon-expandable TAVI $\cdot$ Self-expandable TAVI

\begin{tabular}{|c|c|}
\hline \multicolumn{2}{|c|}{ Abbreviations } \\
\hline $\mathrm{BE}$ & Balloon-expandable \\
\hline BEV & Balloon-expandable valve \\
\hline CI & Confidence interval \\
\hline EuroSCORE & $\begin{array}{l}\text { European system for cardiac operative risk } \\
\text { evaluation }\end{array}$ \\
\hline JBI & $\begin{array}{l}\text { Joanna Briggs institute critical appraisal } \\
\text { checklist for studies reporting prevalence } \\
\text { data }\end{array}$ \\
\hline PRISMA & $\begin{array}{l}\text { Preferred items for reporting of systematic } \\
\text { reviews and meta-analyses }\end{array}$ \\
\hline $\mathrm{RR}$ & Risk ratio \\
\hline OR & Odds ratio \\
\hline SAVR & Surgical aortic valve replacement \\
\hline SE & Self-expandable \\
\hline SEV & Self-expandable valve \\
\hline STS score & The society thoracic of surgeons score \\
\hline TAVI & Transcatheter aortic valve implantation \\
\hline VARC & Valve academic research consortium \\
\hline
\end{tabular}

\section{Introduction}

Since the first-in-man transcatheter aortic valve implantation (TAVI) performed in Rouen in 2002, TAVI has radically transformed the treatment of aortic valve stenosis [1].
Nowadays, the indication for interventional aortic valve replacement is expanded from patients with high to intermediate perioperative risks [2,3]. The recently published PARTNER 3 trial even testified a superior overall outcome, regarding a composite endpoint of death, stroke or rehospitalization, in patients with aortic valve stenosis and low perioperative risk undergoing TAVI compared to surgical aortic valve replacement (SAVR) [4]. Currently, several approved valve deployment systems from different manufactures are on the market and simplified, most can be divided into selfexpandable (SEV) and balloon-expandable (BEV) valves.

Stroke is a major and one of the most feared complications after transcatheter aortic valve implantation (TAVI) and part of the updated endpoint definitions established by the valve academic research consortium (VARC-2) [5]. Stroke, in general, is a major limitation for quality of life and a cost-effective complication [6, 7].

A large meta-analysis by Shah et al. from 2018 determined a periinterventional risk of stroke within the first 30 days of $2.7 \%$ after TAVI [8]. Stroke within the early phase post TAVI occurs likely implantation and devices related, whereas stroke occurring later is regarded to be associated with individual patient's risk factors and long-term valve performance [9].

However, so far it remains uncertain, whether self- or balloon-expandable valves perform differently concerning 
30-day stroke incidence. To investigate, whether SEV or BEV has the greater risk for stroke within the first 30 days after procedure with a transfemoral approach, we performed a meta- and network meta-analysis of the recent literature.

\section{Methods}

The primary outcome of interest was the 30-day incidence of postoperative stroke after transfemoral TAVI with BEV and SEV. Randomized controlled and propensity pair-matched studies with at least 40 patients per group published in English from the time of the first TAVI procedure in 2002 until November 29, 2019 were included. Only studies reporting the 30-day stroke incidence in a head-to-head comparison of SEV and BEV were included, whereas studies comparing TAVI with surgical aortic valve replacement were excluded from analysis. Furthermore, studies or registries not reporting the outcome of transfemoral and transapical TAVI separately were not considered for analysis. Only studies reporting the procedural outcome according to the standardized VARC-2 criteria (or first VARC criteria for older studies) were included [5, 10]. According to VARC-2 criteria, periprocedural stroke is determined clinically or by neuroimaging. Diagnosis must be confirmed by a neurologist or neurosurgical specialist or by a neuroimaging procedure, but stroke may be diagnosed on clinical grounds alone. For network meta-analysis, studies comparing different SEV valves in a head-to-head comparison were also included. Because of inconsistency in direct and indirect estimates, trials comparing SAVR with BEV or SEV, such as the PARTNER trial series and the SURTAVI trial, were not considered for network meta-analysis [9, 11-14]. Three databases, MEDLINE/Pubmed, ClinicalTrials.gov and Cochrane Library, were searched applying predefined key search terms that are presented in the Supplements. Studies were screened at title/abstract level by two independent reviewers (PCS and SMP). Studies matching the inclusion criteria were analyzed at full text level and the quality of evidence was assessed keeping with the Joanna Briggs Institute (JBI) Critical Appraisal Checklist for Studies Reporting Prevalence Data (Supplement Table 1) and Preferred Items for Reporting of Systematic Reviews and Meta-analyses (PRISMA) [15, 16]. Disagreements between the reviewers were resolved through discussion. Meta- and network metaanalysis were carried out using statistical analysis software $\mathrm{R}$ (Version 3.6.1, "meta" and "netmeta" package, r-project. org). For meta-analysis, more conservatively random effects models were used due to heterogeneity in study methodology and population and risk ratios were calculated (RRs). Heterogeneity and among study variance were assessed by calculating Cochran's $\mathrm{Q}, \mathrm{I}^{2}$ and $\tau^{2}$ (Sidik-Jonkman estimator) [17]. Specifically, I-squared $>50 \%$ was considered evidence of moderate or severe inconsistency. To compare different types of valves, a random effects network metaanalysis based on a frequentist framework for indirect and mixed comparisons was applied and reported odds ratios (ORs). First, we generated a comparison-adjusted funnel plot to assess potential publication bias and plot asymmetry was evaluated by Egger's Test [18] (Supplements, Fig. 1). Heterogeneity and among study variance were estimated as described above. Additionally, net heat and net splitting were generated to determine study network inconsistency. Using P-Score, the relative ranking probability of each valve was estimated, and the hierarchy of competing valves was obtained. Shortly, P-scores estimate the probability for each treatment of being better than the competing treatments. However, P-score ranking probability does not correlate with relative treatment effects and cannot be interpreted clinically.

\section{Results}

Overall, a total of 2723 citations were initially retrieved and 9 studies were finally included according to pre-specified criteria, with a total of 3096 patients (1351 patients receiving SEV and 1745 patients receiving BEV (Table 1, Figs. 1, 2 ). Out of these nine selected studies, only two had randomized controlled character (Abdel-Wahab et al. 2014 and Lanz et al. 2019) [19, 20], whereas in seven patient propensity score matching was conducted to adjust for baseline characteristics. For meta-analysis, seven studies comparing head-to-head SEV and BEV were included [19-25], whereas for network analysis all nine studies were considered, including two studies comparing different SEV [26, 27]. Five studies reported the outcome of patients with intermediate, two with low, one with low to intermediate and one with high operative risk according to the operative risk models STS score (The Society Thoracic of Surgeons Score, Table 1) [28]. If STS score was not specified, EuroSCORE and EuroSCORE II were used for risk classification (European System for Cardiac Operative Risk Evaluation) [29, 30]. Thirtyday stroke incidence varied in procedures with SEV from $0 \%$ (CoreValve, Evolute R, ACURATEneo) to 2.9\% (Portico) and in BEV from 0\% (SAPIEN 3) to 5.8\% (SAPIEN XT, Table 1).

Meta-analysis revealed a pooled thirty-day incidence of stroke of $1.8 \%$ in SEV (20 out of 1099) and 3.1\% in BEV (42 out of 1349) resulting in a RR of 0.62 [95\% confidence interval (CI) 0.49-0.80, $p$ value 0.004, Fig. 3] in favor for SEV. Between-study heterogeneity was low, as indicated by $I^{2}(0 \%)$ and $\tau^{2}(0.095, p=0.99)$. Prediction interval presents the expected range of true effects in similar studies and ranged from 0.43 to 0.91 (Table 2).

Nine studies were included for network meta-analysis addressing head-to head comparison of SEV with BEV by 


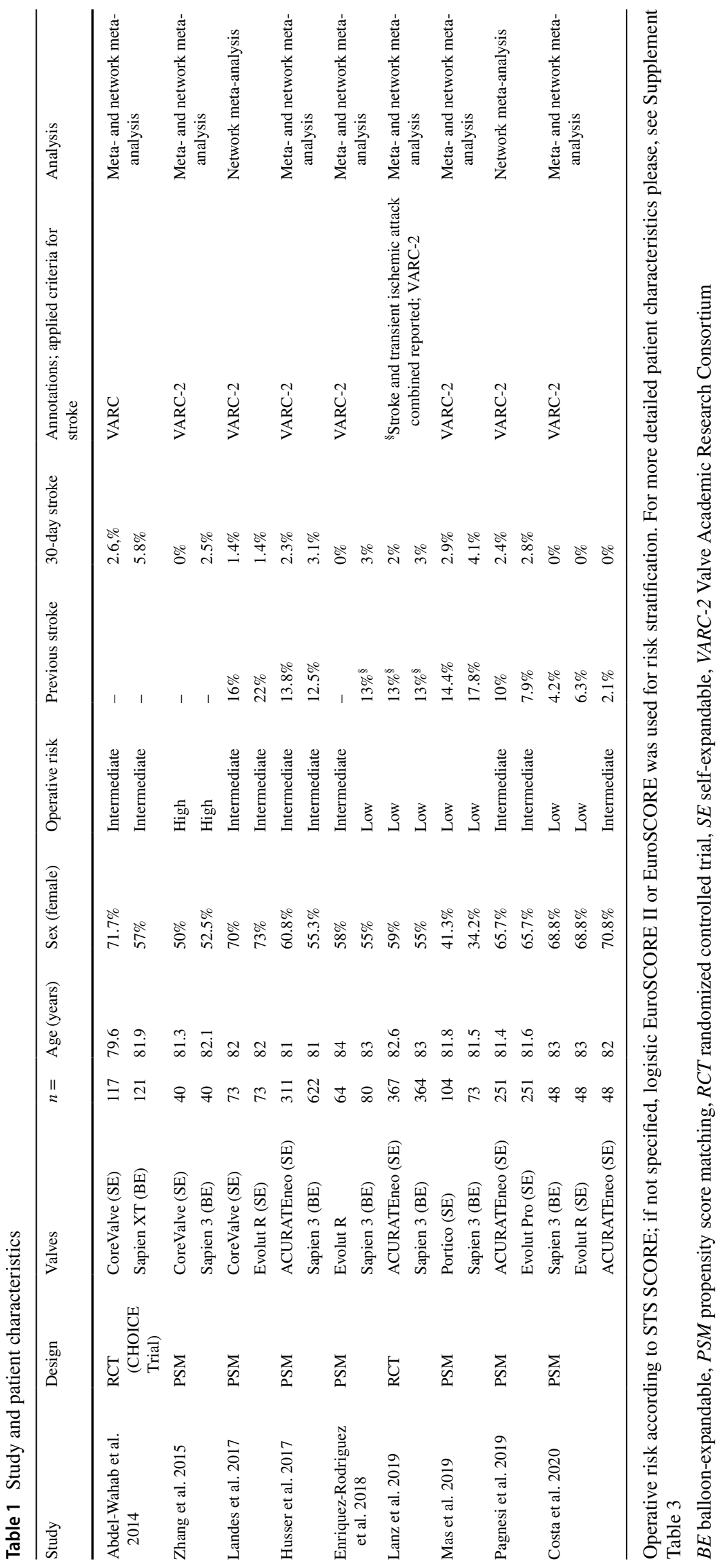




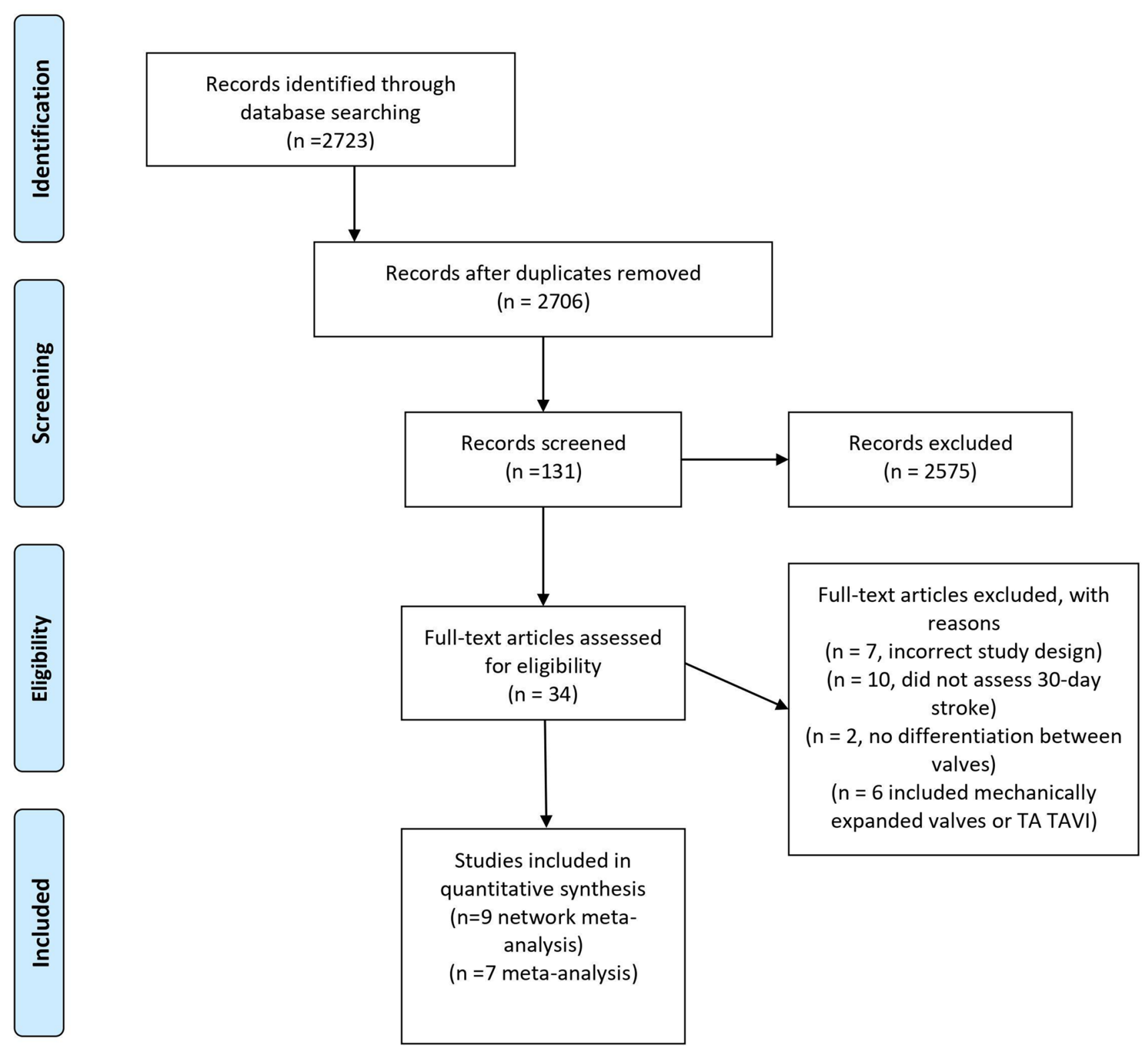

Fig. 1 PRISMA search protocol. Data bases screened: MEDLINE/ Pubmed, ClinicalTrials.gov and Cochrane Library. Detailed search protocol with applied search terms can be found in Supplements. For meta-analysis, only studies with head-to-head comparison of

combining direct and indirect comparisons. Relevant study heterogeneity and inconsistency could be ruled out (Supplement Figs. 1, 2 and 3). In accordance with the estimated P-Score, Medtronic CoreValve was best effective for a reduction of 30-day stroke $(75.2 \%$, pooled stroke incidence $1.7 \%)$, whereas the worst were SAPIEN 3 and XT $(19.0 \%$, pooled stroke incidence $3.1 \%$ Fig. 4 a). However, combined direct and indirect evidence showed no inferiority of SAPIEN valves in head-to-head comparison with CoreValve (OR $2.24,95 \%$ CI 0.70-1.7.20) concerning 30-day stroke incidence (Fig. 4b).
SEV and BEV were included, whereas for network meta-analysis also studies comparing different SEV were considered. $B E V$ balloonexpandable valve, $T A$ transapical, TAVI transcatheter aortic valve implantation, $S E V$ self-expandable valve

\section{Discussion}

Stroke after transfemoral TAVI is a potentially life-threatening and quality of life-impacting event. Although the incidence of stroke following TAVI declines continuously in recent years, it remains a significant cause of mortality and morbidity. The question, whether SEV or BEV has different early-phase stroke rates post TAVI, has been not sufficiently addressed yet.

Our analysis reveals some interesting findings. First, we found a significantly reduced 30-day incidence of stroke 
Fig. 2 Study network. Study network displaying direct (connection) and indirect evidence (over network link). Thickness of lines corresponds to number of specific comparisons

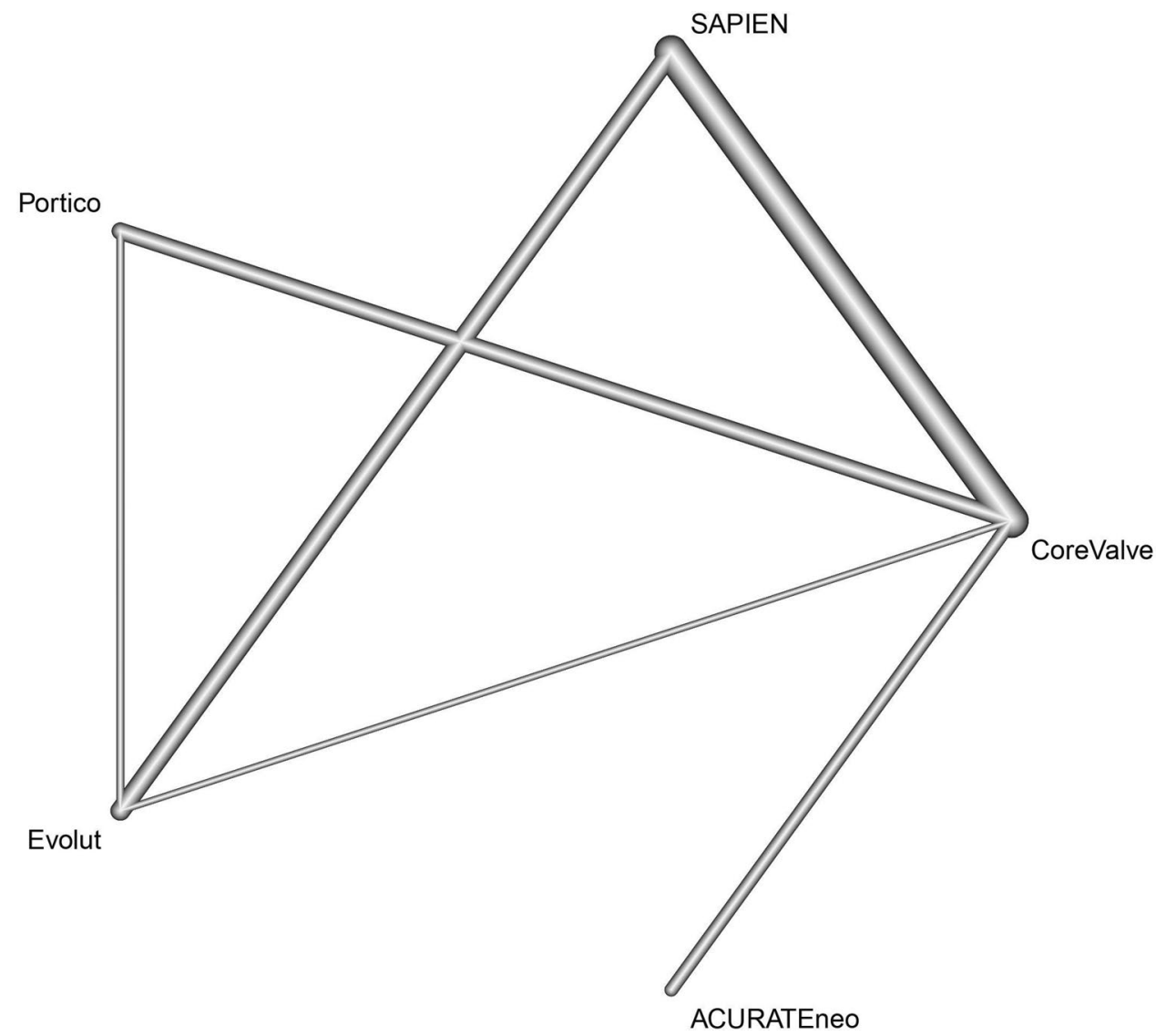

\section{Study}

Zhang 2015

Rodriguez 2018

Abdel-Wahab 2014

Lanz 2019

Mas 2019

Husser 2017

Costa 2020

Random effects model Prediction interval

Heterogeneity: $I^{2}=0 \%, \tau^{2}=0.0095, p=0.99$

Fig. 3 Meta-analysis comparing SEV and BEV concerning incidence of 30-day stroke. Meta-analysis revealed favorable 30-day incidence of stroke after TAVI with SE compared to BE valves (RR $0.6295 \%$ -

after transfemoral TAVI with SEV compared to BEV, resulting in a relative risk reduction of $38 \%$ in favor for SEV. Overall, 30-day stroke incidence was low after TAVI in both SEV (1.8\%) as well as after BEV (3.1\%) and varied significantly between the different included studies. Different to our results, a meta-analysis by Agarwal et al.

040

$0 \quad 64$

$\begin{array}{ll}3 & 117 \\ 7 & 367\end{array}$

$\begin{array}{ll}7 & 311\end{array}$

$\begin{array}{ll}3 & 74\end{array}$

19622

$0 \quad 48$

1349

\section{SE valve BE valve Events Total Events Total}

$\begin{array}{ll}7 & 367 \\ 3 & 104\end{array}$
Risk Ratio

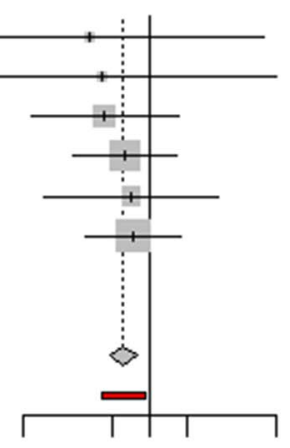

$\begin{array}{llll}0.1 & 0.512 & 10\end{array}$
$\mathbf{R}$

$0.33 \quad[0.01 ; 7.94] \quad 2.8 \%$

$0.42[0.02 ; 10.04] \quad 2.8 \%$

$0.44[0.12 ; 1.67] \quad 15.7 \%$

$0.63[0.25 ; 1.61] \quad 30.9 \%$

$0.71[0.15 ; 3.43] 11.2 \%$

$0.74[0.31 ; 1.73] \quad 36.7 \%$

$0.0 \%$

$0.62[0.49 ; 0.80] 100.0 \%$ $[0.43 ; 0.91]$
CI 0.49-0.8, overall $p=0.0043$; Cochrane's $Q=0.64, p=0.986$ ). $B E$ balloon-expandable, $R R$ risk ratio, $S E$ self-expandable, TAVI transcatheter aortic valve implantation

reported a similar 30-day stroke incidence for transfemoral TAVI with BEV and SEV of 2.6\% [31]. Important to note, different to our analysis, this study included also multicenter registries. Moreover, distribution analysis of the pooled estimates indicated significant heterogeneity. 
Table 2 Net league

\begin{tabular}{lllll}
\hline ACURATEneo &. & $0.85(0.28 ; 2.58)$ &. & $0.68(0.36 ; 1.30)$ \\
$1.46(0.40 ; 5.27)$ & CoreValve & $1.00(0.06 ; 16.30)$ &. & $0.41(0.12 ; 1.46)$ \\
$0.97(0.36 ; 2.62)$ & $0.66(0.15 ; 2.90)$ & Evolut &. & $0.41(0.02 ; 10.26)$ \\
$0.93(0.16 ; 5.31)$ & $0.64(0.09 ; 4.72)$ & $0.96(0.13 ; 6.89)$ & Portico & $0.70(0.14 ; 3.58)$ \\
$0.65(0.35 ; 1.22)$ & $0.45(0.14 ; 1.44)$ & $0.68(0.22 ; 2.05)$ & $0.70(0.14 ; 3.58)$ & SAPIEN \\
\hline
\end{tabular}

Net league reporting the estimated pooled effect sizes (OR with $95 \% \mathrm{CI}$ ) generated by direct comparisons (upper triangle, gray background) and by combination of direct and indirect comparisons (lower triangle, white background)

A P-score for ranking of favorable 30-day stroke incidence

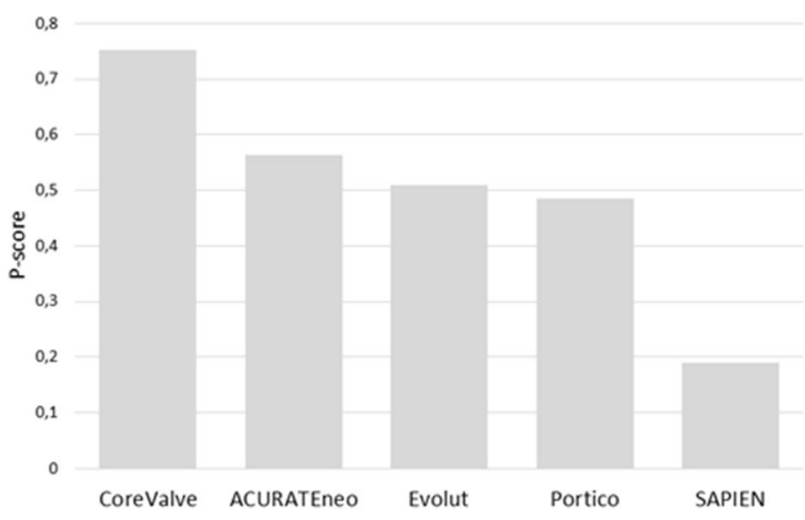

B

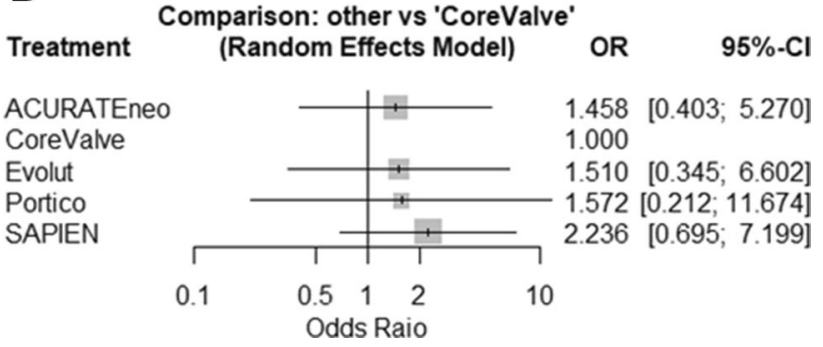

Fig. 4 30-day stroke incidence in competitive valves: a According to P-score derived from random effect frequentist analysis, CoreValve showed the best performance regarding incidence of 30-day stroke. b Pooled analysis demonstrated no superior treatment effect of self-expandable CoreValve concerning 30-day incidence of stroke compared to other self-expandable or balloon-expandable valves (Cochrane's $Q=0.34, p=0.987, I^{2}=0 \%$ and $\tau^{2}=0 \%$ ). $O R$ odds ratio

Second, our mixt-treatment analysis revealed the best performance concerning 30-day stroke for self-expandable CoreValve. We calculated a pooled 30-day stroke incidence for CoreValve of $1.7 \%$, remarkably superior to the stroke rate of the randomized controlled COREVALVE trial, comparing TAVI versus SAVR, that reported a risk of disabling stroke at 30-day follow-up of 3.9\% for TAVI with CoreValve in year 2014. Our meta-analysis revealed for SAPIEN valves the worst performance of all investigated valves (pooled 30-day stroke incidence $3.1 \%$ ). Contrary to our findings, the consecutive randomized controlled PARTNER trials recorded significantly improved stroke rates over the years. The most recent PARTNER 3 trial set a new remarkable benchmark for TAVI procedures and reported a 30-day stroke rate of $0.6 \%$ with the balloon-expandable SAPIEN 3 . However, it is important to note that this was observed in patients with low operative risk as indicated by a median STS score of $1.9 \%$ [32]. Nevertheless, due to the different study design comparing TAVI with SAVR or best medical therapy, the PARTNER trials with remarkable outcome results, especially of the recent one, were not included in our study.

Third, CoreValve was the best effective of the investigated valves to reduce 30-day stroke rate. Nonetheless, in head-tohead comparison we could not proof superiority of one valve over another. A network meta-analysis by Biondi-Zoccai et al. compared the outcome of TAVI vs. SAVR and included four RCT with different follow-up periods (CHOICE trial, PARTNER Cohort A trial, STACCATO trial, US CoreValve trial) [33]. In a sub-analysis, CoreValve demonstrated lower stroke incidence after transfemoral TAVI than SAPIEN valves (OR 0.32, 95\% CI 0.13-0.73) after a median followup of 8 months (ranging from 1 to 12 months). Comparatively, a pooled analysis of 5097 patients by Eggebrecht et al. reported a higher stroke rate after TAVI with SAPIEN compared to CoreValve (3.5\% vs. $1.5 \%$ ), whereas another meta-analysis by Athappan et al. differentiated between multi- and single-center experience and suggested similar risk of 30-day stroke for CoreValve and SAPIEN valves (OR $1.10,95 \%$ CI $0.79-1.15$ and OR $1.28,95 \%$ CI $0.43-3.81$, respectively) [34]. As the TAVI technology and learning curves continue to advance, randomized controlled trials comparing the newer, improved SEV and BEV are needed to finally address this open question directly.

What are the pathophysiological mechanisms of stroke during the early phase of TAVI procedures? Plausible causes of brain injury during TAVI are dysregulated cerebral perfusion, such as hypoperfusion or hypertension, hemorrhagic complications with potential relation to anticoagulation and emboli [35]. Manipulation of the aortic root and aortic arch and navigation of catheters and wires across the aortic valve can provoke embolization. Implantation of both SEV and BEV can cause embolization but highly likely with differences in timing. Kahlert et al. performed transcranial Doppler examinations during TAVI and reported that risk of embolization 
with SEV valves is increased during slow stepwise implantation and with BEV during valve positioning prior to final implantation [36]. Implantation of BEV requires rapid ventricular pacing for stabilization of the aortic root and accurate positioning of the prosthesis. Rapid ventricular pacing causes a state of low to no cardiac output resulting in cerebral hypoperfusion and may be associated with increased stroke risk [37, 38]. Balloon post-dilatation is routinely applied with SEV and $\mathrm{BEV}$ to reduce paravalvular leak and has been described as predictor for acute cerebrovascular events [39].

Although we made efforts to restrict limitations typical for all meta-analyses and mixed treatment comparisons by addressing Preferred Reporting Items for Systematic Reviews and Meta-analyses guidelines, determining source of heterogeneity and publication bias, this study has unavoidable limitations. Although we only included randomized controlled trials and propensity score matched studies addressing a direct comparison of SEV and BEV, the effects of different baseline characteristics on stroke incidence cannot be fully assessed. The median operative risk, assessed by EuroScore and STS score, was heterogenous in the included studies. Several randomized controlled TAVI trials compared TAVI vs. SAVR, such as the PARTNER trial series and the SURTAVI trial [9, 11-14]. Due to our chosen inclusion criteria and because of inconsistency in direct and indirect estimates, trials comparing SAVR with BEV or SEV were not considered for our analysis. Furthermore, we noted a variability in the definition and specification of stroke. Only trials reporting stroke incidence according to the VARC criteria were included. Seven trials reported outcomes according to the recent VARC-2 criteria and one trial according to the first and older VARC criteria published in 2011 [5, 10]. Nevertheless, the included studies did not report in detail how stroke was diagnosed, either by neurological assessment or neuroimaging procedures, a circumstance that arises possible ascertainment bias.

\section{Conclusion}

Stroke after TAVI remains a pivotal clinical complication significantly impacting mortality and morbidity. Our metaanalysis indicates a higher 30-day incidence of stroke after transfemoral TAVI with BEV compared to SEV. Furthermore, we could not find evidence for superiority of a specific valve system. There is a need for more randomized controlled trials with head-to-head comparison of SE and $\mathrm{BE}$ valves to address this open question.

Funding Open Access funding enabled and organized by Projekt DEAL.

Data availability Upon request.
Code availability Please see "Supplementary material".

\section{Compliance with ethical standards}

Conflict of interest P.C.S. was sponsored for medical conferences by Abbott, KelCon, Medos Novartis. S.M.P. was supported by research grants by the Cardiopulmonary Institute (CPI) and the German Centre for Cardiovascular Research (DZHK). M.V.-N. is proctor for Abbott, Boston Scientific, Edwards Lifesience and Medtronic. All other authors have no conflicts of interest related to the subject of the article.

Open Access This article is licensed under a Creative Commons Attribution 4.0 International License, which permits use, sharing, adaptation, distribution and reproduction in any medium or format, as long as you give appropriate credit to the original author(s) and the source, provide a link to the Creative Commons licence, and indicate if changes were made. The images or other third party material in this article are included in the article's Creative Commons licence, unless indicated otherwise in a credit line to the material. If material is not included in the article's Creative Commons licence and your intended use is not permitted by statutory regulation or exceeds the permitted use, you will need to obtain permission directly from the copyright holder. To view a copy of this licence, visit http://creativecommons.org/licenses/by/4.0/.

\section{References}

1. Cribier A, Eltchaninoff H, Bash A, Borenstein N, Tron C, Bauer F et al (2002) Percutaneous transcatheter implantation of an aortic valve prosthesis for calcific aortic stenosis: first human case description. Circulation. 106:3006-3008

2. Baumgartner H, Falk V, Bax JJ, De Bonis M, Hamm C, Holm PJ et al (2017) ESC/EACTS guidelines for the Management of Valvular Heart Disease. Rev Esp Cardiol (Engl Ed) 71:110

3. Nishimura RA, Otto CM, Bonow RO, Carabello BA, Erwin JP, Fleisher LA et al (2017) AHA/ACC focused update of the 2014 AHA/ACC guideline for the Management of Patients with Valvular Heart Disease: a report of the American College of Cardiology/American Heart Association task force on clinical practice guidelines. Circulation 2017:135

4. Mack MJ, Leon MB, Thourani VH, Makkar R, Kodali SK, Russo $M$ et al (2019) Transcatheter aortic-valve replacement with a balloon-expandable valve in low-risk patients. N Engl J Med 380:1695-1705

5. Kappetein AP, Head SJ, Genereux P, Piazza N, van Mieghem NM, Blackstone EH et al (2012) Updated standardized endpoint definitions for transcatheter aortic valve implantation: the valve academic research Consortium- 2 consensus document. Eur Heart J 33:2403-2418

6. Carod-Artal FJ, Egido JA (2009) Quality of life after stroke: The importance of a good recovery. Cerebrovasc Dis 27:204-214

7. Luengo-Fernandez R, Gray AM, Rothwell PM (2009) Costs of stroke using patient-level data: a critical review of the literature. Stroke 40:e18-e23

8. Shah K, Chaker Z, Busu T, Badhwar V, Alqahtani F, Alvi M et al (2018) Meta-analysis comparing the frequency of stroke after Transcatheter versus surgical aortic valve replacement. Am J Cardiol 122:1215-1221

9. Smith CR, Leon MB, Mack MJ, Miller DC, Moses JW, Svensson LG et al (2011) Transcatheter versus surgical aortic-valve replacement in high-risk patients. N Engl J Med 364:2187-2198 
10. Leon MB, Piazza N, Nikolsky E, Blackstone EH, Cutlip DE, Kappetein AP et al (2011) Standardized endpoint definitions for transcatheter aortic valve implantation clinical trials: a consensus report from the valve academic research consortium. J Am Coll Cardiol 57:253-269

11. Reardon MJ, Van Mieghem NM, Popma JJ, Kleiman NS, Søndergaard L, Mumtaz M et al (2017) Surgical or Transcatheter aortic-valve replacement in intermediate-risk patients. $\mathrm{N}$ Engl J Med 376:1321-1331

12. Mack MJ, Leon MB, Thourani VH, Makkar R, Kodali SK, Russo $M$ et al (2019) Transcatheter aortic-valve replacement with a balloon-expandable valve in low-risk patients. N Engl J Med 380:1695-1705

13. Masson J-B, Kovac J, Schuler G, Ye J, Cheung A, Kapadia S et al (2009) Transcatheter aortic valve implantation: review of the nature, management, and avoidance of procedural complications. JACC Cardiovasc Interv 2:811-820

14. Webb JG, Doshi D, Mack MJ, Makkar R, Smith CR, Pichard AD et al (2015) A randomized evaluation of the SAPIEN XT Transcatheter heart valve system in patients with aortic stenosis who are not candidates for surgery. JACC Cardiovasc Interv 8:1797-1806

15. Munn Z, Moola S, Riitano D, Lisy K (2014) The development of a critical appraisal tool for use in systematic reviews addressing questions of prevalence. Int J Health Policy Manag 3:123-128

16. Liberati A, Altman DG, Tetzlaff J, Mulrow C, Gøtzsche PC, Ioannidis JPA et al (2009) The PRISMA statement for reporting systematic reviews and meta-analyses of studies that evaluate healthcare interventions: explanation and elaboration. BMJ 339:b2700

17. Higgins JPT, Thompson SG, Deeks JJ, Altman DG (2003) Measuring inconsistency in meta-analyses. Br Med J 327:557-560

18. Salanti G, Del Giovane C, Chaimani A, Caldwell DM, Higgins JPT (2014) Evaluating the quality of evidence from a network meta-analysis. PLoS One 9:g1741-g1741

19. Abdel-Wahab M, Mehilli J, Frerker C, Neumann F-J, Kurz T, Tolg R et al (2014) Comparison of balloon-expandable vs selfexpandable valves in patients undergoing transcatheter aortic valve replacement: the CHOICE randomized clinical trial. JAMA 311:1503-1514

20. Lanz J, Kim W-K, Walther T, Burgdorf C, Mollmann H, Linke A et al (2019) Safety and efficacy of a self-expanding versus a balloon-expandable bioprosthesis for transcatheter aortic valve replacement in patients with symptomatic severe aortic stenosis: a randomised non-inferiority trial. Lancet (London, England) 394:1619-1628

21. Zhang Y, Pyxaras SA, Wolf A, Schmitz T, Naber CK (2015) Propensity-matched comparison between direct flow medical, Medtronic Corevalve, and Edwards Sapien XT prostheses: device success, thirty-day safety, and mortality. Catheter Cardiovasc Interv 85:1217-1225

22. Enriquez-Rodriguez E, Amat-Santos IJ, Jimenez-Quevedo P, Martin-Morquecho I, Tirado-Conte G, Perez-Vizcayno MJ et al (2018) Comparison of the hemodynamic performance of the balloon-expandable SAPIEN 3 versus Self-Expandable Evolut R transcatheter valve: a case-matched study. Rev Esp Cardiol (Engl Ed) 71:735-742

23. Mas-Peiro S, Seppelt PC, Weiler H, Mohr G-L, Papadopoulos N, Walther $\mathrm{T}$ et al (2019) A direct comparison of self-expandable portico versus balloon-expandable Sapien 3 devices for transcatheter aortic valve replacement: a case-matched cohort study. J Invasive Cardiol 31:E199-E204

24. Husser O, Kim W-K, Pellegrini C, Holzamer A, Walther T, Mayr $\mathrm{PN}$ et al (2017) Multicenter comparison of novel self-expanding versus balloon-expandable transcatheter heart valves. JACC Cardiovasc Interv 10:2078-2087
25. Costa G, Buccheri S, Barbanti M, Picci A, Todaro D, Di Simone E et al (2020) Outcomes of three different new generation transcatheter aortic valve prostheses. Catheter Cardiovasc Interv 95:398-407

26. Landes U, Bental T, Barsheshet A, Assali A, Vaknin Assa H, Levi A et al (2017) Comparative matched outcome of Evolut-R vs CoreValve Transcatheter aortic valve implantation. J Invasive Cardiol 29:69-74

27. Pagnesi M, Kim W-K, Conradi L, Barbanti M, Stefanini GG, Zeus $\mathrm{T}$ et al (2019) Transcatheter aortic valve replacement with next-generation self-expanding devices: a multicenter, retrospective, propensity-matched comparison of Evolut PRO versus Acurate neo Transcatheter heart valves. JACC Cardiovasc Interv 12:433-443

28. O'Brien SM, Shahian DM, Filardo G, Ferraris VA, Haan CK, Rich JB et al (2009) The Society of Thoracic Surgeons 2008 cardiac surgery risk models: part 2-isolated valve surgery. Ann Thorac Surg 88:S23-S42

29. Nashef SAM, Roques F, Michel P, Gauducheau E, Lemeshow S, Salamon R (1999) European system for cardiac operative risk evaluation (EuroSCORE). Eur J Cardio-Thoracic Surg 16:9-13

30. Nashef SAM, Roques F, Sharples LD, Nilsson J, Smith C, Goldstone AR et al (2012) EuroSCORE II. Eur J Cardio-Thoracic Surg. 41:734-745

31. Agarwal S, Parashar A, Kumbhani DJ, Svensson LG, Krishnaswamy A, Tuzcu EM et al (2015) Comparative meta-analysis of balloon-expandable and self-expandable valves for transcatheter aortic valve replacement. Int J Cardiol 197:87-97

32. Mack MJ, Leon MB, Thourani VH, Makkar R, Kodali SK, Russo $M$ et al (2019) Transcatheter aortic-valve replacement with a balloon-expandable valve in low-risk patients. N Engl J Med 380:1695-1705

33. Biondi-Zoccai G, Peruzzi M, Abbate A, Gertz ZM, Benedetto U, Tonelli E et al (2014) Network meta-analysis on the comparative effectiveness and safety of transcatheter aortic valve implantation with CoreValve or Sapien devices versus surgical replacement. Hear Lung Vessel 6:232-243

34. Athappan G, Gajulapalli RD, Sengodan P, Bhardwaj A, Ellis SG, Svensson L et al (2014) Influence of transcatheter aortic valve replacement strategy and valve design on stroke after transcatheter aortic valve replacement: a meta-analysis and systematic review of literature. J Am Coll Cardiol 63:2101-2110

35. Tay ELW, Gurvitch R, Wijesinghe N, Nietlispach F, Wood D, Cheung A et al (2011) A high-risk period for cerebrovascular events exists after transcatheter aortic valve implantation. JACC Cardiovasc Interv 4:1290-1297

36. Kahlert P, Al-Rashid F, Döttger P, Mori K, Plicht B, Wendt D et al (2012) Cerebral embolization during transcatheter aortic valve implantation: a transcranial doppler study. Circulation 126:1245-1255

37. Seppelt PC, Mas-Peiro S, De Rosa R, Murray IM, Arsalan M, Holzer L et al (2020) Dynamics of cerebral oxygenation during rapid ventricular pacing and its impact on outcome in transfemoral transcatheter aortic valve implantation. Catheter Cardiovasc Interv 2020:ccd.28975

38. Szeto WY, Augoustides JG, Desai ND, Moeller P, McGarvey ML, Walsh E et al (2011) Cerebral embolic exposure during transfemoral and transapical transcatheter aortic valve replacement. J Card Surg 26:348-354

39. Nombela-Franco L, Webb JG, De Jaegere PP, Toggweiler S, Nuis RJ, Dager AE et al (2012) Timing, predictive factors, and prognostic value of cerebrovascular events in a large cohort of patients undergoing transcatheter aortic valve implantation. Circulation 126:3041-3053 